\title{
Comparison of the diagnostic values of circulating steroid hormones, VEGF-A, PIGF, and ADAM12 in women with ectopic pregnancy
}

\author{
Shien Zou' ${ }^{1}$ Xin Li ${ }^{1}$, Yi Feng ${ }^{2,3}$, Shan Sun ${ }^{4}$, Jin Li ${ }^{5}$, Emil Egecioglư ${ }^{2}$, Håkan Billig $^{2}$ and Ruijin Shao ${ }^{2 *}$
}

\begin{abstract}
Background: Several peripheral proteins that might be useful for detecting the presence of ectopic pregnancy (EP) have been evaluated, but none have been proven entirely useful in the clinic. We investigated the presence and the possible changes in circulating molecules that distinguish between normal intrauterine pregnancy (IUP) and tubal ectopic pregnancy.

Methods: Non-pregnant women during the menstrual cycle, women with IUP, and women with tubal EP after informed consent. Serum levels of $17 \beta$-estradiol (E2), progesterone (P4), testosterone (T), beta-human chorionic gonadotropin ( $\beta-h C G)$, vascular endothelial growth factor-A (VEGF-A), placental growth factor (PIGF), and a distintegrin and metalloprotease protein 12 (ADAM12) were analyzed. Receiver operating characteristic analysis was used to assess the diagnostic discrimination of EP and gestational age-matched IUP.

Results: E2, P4, PIGF, and ADAM12 levels increased and $\beta$-hCG decreased throughout IUP. E2 and VEGF-A levels were significantly different between women with tubal EP and IUP. However, using a serum $\beta$-hCG cut-off of less than $1000 \mathrm{mlU} / \mathrm{mL}$, P4 was significantly lower in women with tubal EP compared to IUP. Although E2 was inversely correlated with VEGF-A in women in the early stages of IUP, E2 was not correlated with VEGF-A in women with EP prior to tubal surgery. There were no significant differences in either PIGF or ADAM12 alone between women with tubal EP or IUP. Although no significant correlations were seen between E2 and PIGF or P4 and ADAM12 in women in the early stages of IUP, E2 was positively correlated with PIGF and P4 was positively correlated with ADAM12 in women with EP prior to tubal surgery. Our studies defined associations but not causality.

Conclusions: Individual measurements of serum E2 or VEGF-A levels are strongly related to early pregnancy outcomes for women with IUP and EP, and pregnancy-associated E2 and VEGF-A levels provide diagnostic accuracy for the presence of tubal EP. This study demonstrates that correlation analysis of E2/NEGF-A and E2/PIGF serum levels may be able to distinguish a tubal EP from a normal IUP.
\end{abstract}

Keywords: Steroid hormones, VEGF-A, PIGF, ADAM12, Hypoxia, Tubal ectopic pregnancy

\section{Background}

Approximately $98 \%$ of ectopic pregnancies (EP) occur in the Fallopian tube [1]. The most significant complication of EP is rupture of the Fallopian tube causing massive internal bleeding, infection, and possibly death [2]. EPs are asymptomatic prior to rupture of the Fallopian tube $[2,3]$ and at present the only way to conclusively diagnose

\footnotetext{
* Correspondence: ruijin.shao@fysiologi.gu.se

${ }^{2}$ Department of Physiology/Endocrinology, Institute of Neuroscience and Physiology, The Sahlgrenska Academy, University of Gothenburg, Gothenburg 40530, Sweden

Full list of author information is available at the end of the article
}

EP is transvaginal ultrasound monitoring, preferably with $\beta$-human chorionic gonadotropin ( $\beta$-hCG) and progesterone (P4) confirmation [3]. Although symptom-based diagnosis of tubal EP has improved [1,4], the diagnosis of EP is not always simple or straightforward. It has been reported that more than one-third of the women who have died from EP in the UK since 1997 had been mis-diagnosed [4]. Although several risk factors for tubal EP have been identified [5-8], the underlying mechanisms leading to tubal EP are not fully understood [1,9]. There is currently no accurate method to identify what treatments for tubal

\section{Ciomed Central}


dysfunction should be undertaken to prevent EP $[1,9]$. Because an early and accurate laboratory diagnosis of tubal EP could assist clinical management, various laboratories have directed their research toward biochemical markers of tubal EP [10-13]. Several peripheral proteins that might be useful for detecting the presence of EP have been evaluated $[14,15]$, but none have been proven entirely useful in the clinic.

The vascular endothelial growth factor (VEGF) family consists of VEGF-A (generally called VEGF), VEGF-B, VEGF-C, VEGF-D, VEGF-E, and placental growth factor (PIGF). These are angiogenic factors that participate in the regulation of early placental angiogenesis and maternal spiral artery remodeling [16]. A disintegrin and metalloprotease protein 12 (ADAM12) is one member of a disintegrin and metalloprotease protein family that possesses extracellular metalloprotease and cell-binding functions as well as intracellular signaling capacities [17]. Although the mechanisms underlying the functional roles of VEGF-A, PIGF, and ADAM12 in tubal EP are not clear, circulating levels of VEGF-A [12,18-23], PIGF [23-25], and ADAM12 [26-28] have been shown to change in women with EP. However, the retrospective case-control studies have yielded inconsistent results for such correlations $[24,27,29]$. The regulatory effects of changes in reproductive steroid hormones or of menstrual cycle phase on the circulating levels of VEGF-A, PIGF, and ADAM12 in women throughout normal intrauterine pregnancy (IUP) and post-term delivery are far less studied and understood. Furthermore, to our knowledge there are no studies making direct comparisons of these candidate protein biomarkers for EP diagnosis within the same cohort.

It has long been recognized that early diagnosis is important for making therapeutic decisions in regards to tubal EP that improve future fertility. Because the measurement of candidate biomarkers in the circulation is a noninvasive procedure and is relatively simple to perform without requiring special instruments and personnel, the development and validation of circulating biomarkers for the early diagnosis of tubal EP is warranted. The present study aimed to evaluate whether circulating hormone (17 $\beta$ estradiol (E2), progesterone (P4), testosterone (T), and $\beta$ hCG), VEGF-A, PIGF, and ADAM12 levels vary in women during the menstrual cycle, in women with IUP, and in women with EP before and after tubal surgeries.

\section{Methods}

\section{Ethics statement}

This study was approved by the Ethics Committees of the Obstetrics and Gynecology Hospital and Shanghai Medical College, Fudan University, China. All participants provided informed consent.

\section{Study design and sample collection}

All participants underwent clinical examination at the Obstetrics and Gynecology Hospital of Fudan University, Shanghai, China. Clinical work-up included menstrual history as well as current cycle length and menstrual regularity.

Exclusion criteria included use of estrogen- or progestincontaining medication within three months of the study, past EP, any gynecological pathology (e.g., endometriosis, fibroids, or any operation to the gynecological organs), infection, and smoking. All the patients whose pregnancies resulted from assisted reproductive technologies were also excluded from the study.

Blood samples were collected into Sarstedt evacuated tubes without anticoagulant. All blood samples were centrifuged at $1000 \times g$ for $15 \mathrm{~min}$, and the serum was stored at $-80^{\circ} \mathrm{C}$ until batch analyses. The present study included non-pregnant and pregnant women (total $\mathrm{n}=$ 153) who were subdivided into the following groups:

Group 1. The different stages of the menstrual cycle in non-pregnant women $(\mathrm{n}=78)$ were studied. Blood samples were collected at the scheduled visits during their menstrual cycle. Menstrual cycle day was established using the criteria reported by Noyes et al. [30]. Sample dating characterized the samples as coming from the proliferative (days $1-14$ of the cycle), early secretive (days 15-18), mid-secretive (days 19-23), and late secretive (days 24-28) phases of the menstrual cycle. Regular menstrual cycles were defined as an average cycle length of 26-30 days, with no more variation than \pm 3 days from the average. Transabdominal ultrasonography was also performed to assess ovarian volume and uterine thickness.

Group 2. This group comprised healthy pregnant women studied longitudinally throughout gestation and post-term delivery ( $\mathrm{n}=42)$. Blood samples were collected at the scheduled visits during their IUP, and on days 1-3 after spontaneous labor and vaginal delivery. The diagnosis of a normal IUP was made upon the observation of an intrauterine gestational sac or a live embryo on the transvaginal or transabdominal ultrasound scan. Only women with normally progressing pregnancies were studied during their visits to the prenatal clinic during the early, middle, and late stages of their IUP.

Group 3. In this group, women with EP $(\mathrm{n}=32)$ were studied before and after tubal surgery and matched to a subgroup of women with early IUP. A full medical history was documented, and clinical examination was carried out by the attending physician. Transvaginal ultrasonography was performed and the serum $\beta$-hCG levels were analyzed in patients at the time of their first clinical presentation. Blood samples were collected from patients at the time of surgery or 2-3 days after surgery. None of the women undergoing surgical management of EP presented with acute hemodynamic shock. Women with EP were 
diagnosed during laparoscopy and on histological examination of the surgical specimens.

\section{Main outcome measures}

All sera were stored at $-80^{\circ} \mathrm{C}$ before performing the assays, and aliquots that had not been previously thawed were used in the present study. Samples were tested in duplicate and analyzed individually. Radioimmunoassays (RIA) were performed at Beijing Free Co. (China), and enzyme-linked immunoassays (ELISA) were performed at the Department of Integrative Medicine and Neurobiology, Shanghai Medical College, Fudan University (China). The averages of the duplicate readings for each standard, control, and individual samples were used for the analyses.

\section{$E 2, P 4, T$, and $\beta$ - $h C G$ assays}

Serum E2 (with an assay sensitivity less than $5.0 \mathrm{pg} / \mathrm{mL}$, an intra-assay coefficient of variation (CV) of $10.0 \%$, and an interassay $\mathrm{CV}$ of $15.2 \%$ ), P4 (with an assay sensitivity less than $5.0 \mathrm{ng} / \mathrm{mL}$, an intra-assay $\mathrm{CV}$ of $5.0 \%$, and an interassay $\mathrm{CV}$ of $10.0 \%$ ), $\mathrm{T}$ (with an assay sensitivity less than $0.1 \mathrm{ng} / \mathrm{mL}$, an intra-assay $\mathrm{CV}$ of $8.0 \%$, and an interassay CV of $15.0 \%$ ), and $\beta$-hCG (with an assay sensitivity less than $10.0 \mathrm{mIU} / \mathrm{mL}$, an intra-assay CV of $5.0 \%$, and an interassay $\mathrm{CV}$ of $10.0 \%$ ) levels were measured by competitive RIA ( ${ }^{125} \mathrm{I}$ - Kit, Beijing Free Co.) using directcoated tube technology. E2, P4, T, and $\beta$-hCG were labeled with ${ }^{125} \mathrm{I}$ as the tracer, and known quantities of unlabeled E2, P4, T, and $\beta$-hCG were used to construct standard curves. The concentrations used for the standard curves were $0-4000 \mathrm{pg} / \mathrm{mL}$ for E2, $0-100 \mathrm{ng} / \mathrm{mL}$ for $\mathrm{P} 4,0-10 \mathrm{ng} / \mathrm{mL}$ for $\mathrm{T}$, and $0-1600 \mathrm{mIU} / \mathrm{mL}$ for $\beta$-hCG.

\section{VEGF-A, PIGF, and ADAM12 assays}

All samples were brought to room temperature and vortexed for $5 \mathrm{~s}$ before applying them to the ELISA plate. Serum levels of VEGF-A (with an assay sensitivity less than $5.0 \mathrm{pg} / \mathrm{mL}$, an intra-assay $\mathrm{CV}$ of $6.7 \%$, and an interassay $\mathrm{CV}$ of $8.8 \%$ ), PIGF (with an assay sensitivity less than $7.0 \mathrm{pg} / \mathrm{mL}$, an intra-assay $\mathrm{CV}$ of $7.0 \%$, and an interassay CV of $11.8 \%$ ), and ADAM12 (with an assay sensitivity less than $0.03 \mathrm{ng} / \mathrm{mL}$, an intra-assay $\mathrm{CV}$ of $4.1 \%$, and an interassay $\mathrm{CV}$ of $5.5 \%$ ) were measured by ELISA. The ELISA kits for the three proteins were catalog numbers DVE00, DPG00, and DAD120, respectively, from R\&D Systems, Inc., Minneapolis, MN. Assays were performed as described previously $[21,25,27]$ according to the manufacturer's instructions and with reagents and materials provided by the manufacturer.

\section{Statistical analysis}

Numerical, grouped results are expressed as the mean \pm SEM. In all analyses, a P value less than 0.05 was considered statistically significant. Statistical analysis was performed using SPSS version 16.0 for Windows (SPSS Inc., Chicago, IL). Comparison among the various groups was performed using nonparametric tests (Kruskal-Wallis followed by multiple comparison procedures according to Dunn's method) because our variables did not have a normal distribution. Correlation between variables was performed using Spearman's analysis.

The specificity and sensitivity of the various assays as diagnostic tests were assessed using receiver operating characteristic (ROC) curve analysis [31]. As opposed to accuracy, sensitivity and specificity are not dependent on the prevalence of the disease in the sample. Thus, ROC curve analysis provides a description of disease detectability that is independent of both disease prevalence and decision threshold effects. For ROC analysis, women with EP were considered affected, and IUP as unaffected. ROC curves were constructed by plotting the sensitivity (true-positive) on the ordinate as a function of the complement of specificity (false-positive) for all possible cut-off values of the diagnostic test [32]. Greater deviation toward the left upper corner of the curve indicates better detection of EP.

\section{Results}

The demographics and laboratory characteristics of the normal menstrual cycle women and those with IUP and EP are shown in Table 1 and 2. There were no significant differences in age between the three groups and there were also no significant differences in the number of gestational days in women with EP and early IUP. Consequently, we examined the relationships between hormones and VEGF-A, PIGF, and ADAM12 in these groups using unadjusted Spearman's analysis (Tables 3, 4 and 5).

\section{The menstrual cycle}

Although a nonparametric, unpaired Kruskal-Wallis test did not show significant differences between the four endometrial cycle phases, serum E2 and P4 levels exhibited characteristic changes during the menstrual cycle. The E2: P4 ratio was significantly decreased in the early-, mid-, and late-secretive phases compared to the proliferative phase (Table 1). However, no significant differences in serum $\mathrm{T}$, VEGF-A, PIGF, or ADAM12 levels were observed between any of the phases (Table 1 and 2). There was no significant correlation between steroid hormones (E2, P4, and T) and candidate biomarkers (VEGF-A, PIGF, and ADAM12) in the mid-secretive phase (Tables 3, 4 and 5).

\section{IUP}

Although serum $\mathrm{T}$ levels were not significantly different between early, middle, and late stages of IUP and postterm delivery, serum E2 and P4 levels increased progressively during these stages, peaked in the late stage of IUP, and fell after delivery. Serum $\beta$-hCG levels were 
Table 1 Patient characteristics and hormonal profiles

\begin{tabular}{|c|c|c|c|c|c|c|c|c|}
\hline & $\mathrm{n}$ & $\begin{array}{c}\text { Age } \\
\text { (years) }\end{array}$ & $\begin{array}{c}\mathrm{GA} \\
\text { (days) }\end{array}$ & $\begin{array}{c}\text { E2 } \\
(\mathrm{pg} / \mathrm{mL})\end{array}$ & $\begin{array}{c}\text { P4 } \\
\text { (ng/mL) }\end{array}$ & E2/P4 & $\begin{array}{c}\mathrm{T} \\
(\mathrm{ng} / \mathrm{mL})\end{array}$ & $\begin{array}{c}\beta-\mathrm{hCG} \\
(\mathrm{mlU} / \mathrm{mL})\end{array}$ \\
\hline \multicolumn{9}{|l|}{ Menstrualcycle phase } \\
\hline Proliferative & 30 & $25.90 \pm 0.50$ & - & $37.99 \pm 4.76$ & $0.90 \pm 0.12$ & $0.06 \pm 0.012$ & $0.21 \pm 0.02$ & - \\
\hline Early secretive & 13 & $25.85 \pm 0.55$ & - & $16.84 \pm 4.52$ & $2.59 \pm 0.82$ & $0.01 \pm 0.004^{\boldsymbol{\Lambda}}$ & $0.15 \pm 0.02$ & - \\
\hline Mid secretive & 20 & $25.10 \pm 0.40$ & - & $14.57 \pm 4.15$ & $5.05 \pm 1.02$ & $0.02 \pm 0.008^{\wedge \Lambda}$ & $0.15 \pm 0.05$ & - \\
\hline Late secretive & 15 & $25.80 \pm 1.09$ & - & $14.83 \pm 2.97$ & $3.80 \pm 1.15$ & $0.01 \pm 0.003^{\boldsymbol{\Lambda}}$ & $0.15 \pm 0.04$ & - \\
\hline \multicolumn{9}{|l|}{ Intrauterine pregnancy } \\
\hline Early & 14 & $26.36 \pm 1.46$ & $50.57 \pm 1.36$ & $176.61 \pm 21.87$ & $13.00 \pm 1.65$ & $0.02 \pm 0.003$ & $0.53 \pm 0.05$ & $21320.76 \pm 1700.47$ \\
\hline Middle & 10 & $27.33 \pm 1.03$ & $115.50 \pm 4.06$ & $211.91 \pm 42.04$ & $15.81 \pm 1.03$ & $0.01 \pm 0.003$ & $0.27 \pm 0.05$ & $17727.61 \pm 2925.63$ \\
\hline Late & 13 & $27.58 \pm 1.08$ & $255.11 \pm 8.16$ & $499.62 \pm 87.98^{\# \# \#}$ & $89.93 \pm 11.99$ \#\#\# & $0.01 \pm 0.003$ & $0.70 \pm 0.08$ & $12311.79 \pm 1644.37^{\# \#}$ \\
\hline Post-term delivery & 10 & $30.70 \pm 1.27$ & - & $39.86 \pm 5.35$ & $6.62 \pm 0.74$ & $0.01 \pm 0.001$ & $0.37 \pm 0.04$ & $3691.29 \pm 816.94$ \#\#\# \\
\hline \multicolumn{9}{|l|}{ Ectopic pregnancy } \\
\hline \multicolumn{9}{|l|}{ Before surgery } \\
\hline$\beta-\mathrm{hCG}<1,000 \mathrm{mlU} / \mathrm{mL}$ & 17 & $29.06 \pm 1.13$ & $48.00 \pm 4.31$ & $36.09 \pm 5.00$ & $3.65 \pm 0.77$ & $0.02 \pm 0.003$ & $0.41 \pm 0.05$ & $813.45 \pm 350.12$ \\
\hline$\beta-h C G \geq 1,000 \mathrm{mlU} / \mathrm{mL}$ & 15 & $31.93 \pm 1.56$ & $47.20 \pm 3.87$ & $33.31 \pm 6.45$ & $6.97 \pm 1.30$ & $0.01 \pm 0.008^{*}$ & $0.48 \pm 0.04$ & $6505.13 \pm 1999.57$ \\
\hline Total & 32 & $30.41 \pm 0.96$ & $47.61 \pm 2.86$ & $34.70 \pm 4.01$ & $5.37 \pm 0.82$ & $0.02 \pm 0.004$ & $0.45 \pm 0.03$ & $3573.05 \pm 1092.31$ \\
\hline \multicolumn{9}{|l|}{ After surgery } \\
\hline$\beta-h C G<500 \mathrm{mlU} / \mathrm{mL}$ & 16 & $29.13 \pm 1.28$ & - & $54.53 \pm 15.90$ & $2.04 \pm 0.38$ & $0.03 \pm 0.006^{*}$ & $0.37 \pm 0.06$ & $237.15 \pm 36.15$ \\
\hline$\beta-h C G \geq 500 \mathrm{mlU} / \mathrm{mL}$ & 6 & $29.50 \pm 1.73$ & - & $26.03 \pm 9.77$ & $2.43 \pm 0.38$ & $0.01 \pm 0.003^{*}$ & $0.26 \pm 0.07$ & $1792.07 \pm 353.56$ \\
\hline Total & 22 & $29.23 \pm 1.02$ & - & $46.75 \pm 12.05$ & $2.14 \pm 0.29$ & $0.02 \pm 0.005$ & $0.34 \pm 0.05$ & $703.63 \pm 192.92$ \\
\hline
\end{tabular}

GA, gestational age. Data are presented as mean \pm SEM. Statistical analysis was performed using SPSS version 16.0 for Windows (SPSS Inc., Chicago, IL). A nonparametric, unpaired test (Kruskal-Wallis test) followed by Dunnett'spost hoc test was used for comparison of continuous variables.

$\Delta \mathrm{p}<0.05, \boldsymbol{\Delta} \boldsymbol{\Delta} \mathrm{p}<0.01$ vs. the proliferative phase of the endometrial cycle; \#\# $p<0.01, \# \# \mathrm{p}<0.001$ vs. the early stage of intrauterine pregnancy;

* $p<0.05$ vs. ectopic pregnancy (before surgery, $\beta-\mathrm{hCG}<1,000 \mathrm{mIU} / \mathrm{mL}$ ).

high in the early stage of IUP and decreased throughout IUP and post-term delivery. Serum PIGF and ADAM12 levels also became progressively higher throughout the course of IUP, and were highest in the late stage of IUP (Table 2). Serum levels of PIGF and ADAM12 decreased after delivery. No significant changes in the E2:P4 ratio or serum $\mathrm{T}$ and VEGF-A levels were observed (Table 1 and 2), but there was a significant correlation between serum E2 and VEGF-A levels in the early stages of IUP $(r=-0.67, \mathrm{P}<0.01)($ Table 3$)$.

\section{Differences between IUP and the mid-secretive phase of the menstrual cycle}

Serum E2 and T levels were significantly higher in the early stage of IUP than in the mid-secretive phase of the menstrual cycle (Figure 1A and C). Serum ADAM12 levels were also significantly higher in women with normal IUP post-term delivery than in women in the midsecretive phase of the menstrual cycle (Figure 1F).

\section{Tubal EP}

Table 1 lists the variations in the serum $\beta$-hCG levels in women with EP before and after tubal surgeries.
Significant differences in the E2:P4 ratios were only observed when using two different cut-off values (500 and $1000 \mathrm{mIU} / \mathrm{mL}$, Table 2). Because the variations in the serum concentrations of E2, P4, T, VEGF-A, PIGF and ADAM12 did not differ in women with EP with different $\beta$-hCG levels within the same surgical group, the results of the two EP subgroups before or after tubal surgery are presented as a total group (Tables 3, 4 and 5, Figure 1 and 2). In contrast to women with EP prior to tubal surgery, serum E2 levels were correlated with serum VEGF-A and ADAM12 levels after tubal surgery $(\mathrm{r}=-0.43, \mathrm{P}=0.05$ (Table 3) and $\mathrm{r}=-0.45, \mathrm{P}=0.04$ (Table 5), respectively). Serum E2 levels were significantly correlated with serum PIGF levels in women with EP both before $(\mathrm{r}=1.00, \mathrm{P}<0.001)$ and after $(\mathrm{r}=-0.48$, $P=0.03$ ) tubal surgeries (Table 4). In contrast to E2, serum P4 levels were significantly correlated with serum ADAM12 levels in women with EP prior to tubal surgery $(\mathrm{r}=1.00, \mathrm{P}<0.001)$ (Table 5 ). Serum $\mathrm{T}$ levels correlated well with serum VEGF-A levels in women with EP prior to tubal surgery $(\mathrm{r}=0.46, \mathrm{P}=0.04)$ (Table 3 ) and with serum PIGF levels after tubal surgery $(\mathrm{r}=-0.44, \mathrm{P}=0.05)($ Table 4). 
Table 2 Patient VEGF-A, PIGF, and ADAM12 levels

\begin{tabular}{|c|c|c|c|c|}
\hline & $\mathrm{n}$ & $\begin{array}{l}\text { VEGF-A } \\
\text { (pg/mL) }\end{array}$ & $\begin{array}{c}\text { PIGF } \\
(\mathrm{pg} / \mathrm{mL})\end{array}$ & $\begin{array}{c}\text { ADAM12 } \\
\text { (ng/mL) }\end{array}$ \\
\hline \multicolumn{5}{|l|}{ Menstrualcycle phase } \\
\hline Proliferative & 30 & $420.74 \pm 31.75$ & $49.64 \pm 1.12$ & $0.94 \pm 0.06$ \\
\hline Early secretive & 13 & $391.59 \pm 50.64$ & $49.16 \pm 3.52$ & $1.41 \pm 0.13$ \\
\hline Mid secretive & 20 & $389.00 \pm 43.50$ & $64.08 \pm 8.32$ & $1.19 \pm 0.15$ \\
\hline Late secretive & 15 & $284.57 \pm 26.72$ & $79.95 \pm 10.05$ & $0.43 \pm 0.04$ \\
\hline \multicolumn{5}{|l|}{ Intrauterine pregnancy } \\
\hline Early & 14 & $169.29 \pm 59.77$ & $43.05 \pm 1.06$ & $2.35 \pm 0.70$ \\
\hline Middle & 10 & $91.33 \pm 3.30$ & $363.42 \pm 160.63^{\# \# \#}$ & $20.43 \pm 3.97$ \\
\hline Late & 13 & $95.13 \pm 4.68$ & $517.87 \pm 85.97^{\# \# \#}$ & $83.12 \pm 13.96^{\# \# \#}$ \\
\hline Post-term delivery & 10 & $661.67 \pm 192.11$ & $46.22 \pm 1.30$ & $41.81 \pm 4.49^{\# \# \#}$ \\
\hline \multicolumn{5}{|l|}{ Ectopic pregnancy } \\
\hline \multicolumn{5}{|l|}{ Before surgery } \\
\hline$\beta-h C G<1,000 \mathrm{mlU} / \mathrm{mL}$ & 17 & $655.76 \pm 56.30$ & $43.88 \pm 1.11$ & $1.35 \pm 0.24$ \\
\hline$\beta-h C G \geq 1,000 \mathrm{mlU} / \mathrm{mL}$ & 15 & $1095.56 \pm 185.03$ & $41.03 \pm 1.49$ & $1.61 \pm 0.29$ \\
\hline Total & 32 & $853.67 \pm 99.62^{* *}$ & $42.60 \pm 0.94$ & $1.46 \pm 0.18$ \\
\hline \multicolumn{5}{|l|}{ After surgery } \\
\hline$\beta-\mathrm{hCG}<500 \mathrm{mlU} / \mathrm{mL}$ & 16 & $1080.63 \pm 150.38$ & $44.99 \pm 1.29$ & $1.33 \pm 0.06$ \\
\hline$\beta-h C G \geq 500 \mathrm{mlU} / \mathrm{mL}$ & 6 & $1584.67 \pm 234.67$ & $46.31 \pm 1.18$ & $1.42 \pm 0.06$ \\
\hline Total & 22 & $1200.63 \pm 133.60^{* * *}$ & $45.30 \pm 1.02$ & $1.35 \pm 0.05$ \\
\hline
\end{tabular}

Data are presented as mean \pm SEM. Statistical analysis was performed using SPSS version 16.0 for Windows (SPSS Inc., Chicago, IL). A nonparametric, unpaired test (Kruskal-Wallis test) followed by Dunnett'spost hoc test was used for comparison of continuous variables. \#\#\# $p<0.001$ vs. the early stage of intrauterine pregnancy; ${ }^{* *} \mathrm{p}<0.01,{ }^{* * *} \mathrm{p}<0.001$ vs. ectopic pregnancy (before surgery, $\beta$-hCG $<1,000$ ).

\section{Differences between tubal EP and the mid-secretive} phase of menstrual cycle

Serum T levels were significantly higher in women with EP before tubal surgery than in women in the midsecretive phase of the menstrual cycle (Figure 1C). Serum VEGF-A levels were significantly higher in women with EP both before and after tubal surgeries than in women in the mid-secretive phase of the menstrual cycle (Figure 1D).

\section{Differences between tubal EP and gestational age- matched IUP}

Women with EP both before and after tubal surgeries had lower levels of E2 than the gestational age-matched women with IUP (Figure 1A). The mean difference in E2 levels between tubal EP before surgery and the early stage of IUP was $139.73 \mathrm{pg} / \mathrm{mL}$ (95\% CI: 95.14-184.31, $\mathrm{P}<0.001)$. There were no significant differences in serum P4 levels in tubal EP compared with the early stage of

Table 3 Correlation between VEGF-A level and hormone concentrations

\begin{tabular}{|c|c|c|c|c|}
\hline & E2 & P4 & $\mathbf{T}$ & $\beta$-hCG \\
\hline \multicolumn{5}{|c|}{ Endometrial cycle phase } \\
\hline Mid secretive & $-0.08(0.75)$ & $0.05(0.83)$ & $-0.25(0.30)$ & n.d. \\
\hline \multicolumn{5}{|c|}{ Intrauterine pregnancy } \\
\hline Early & $-0.67(0.01)$ & $-0.19(0.53)$ & $-0.29(0.34)$ & $0.14(0.65)$ \\
\hline Post-term delivery & $0.42(0.27)$ & $-0.18(0.64)$ & $-0.42(0.26)$ & $-0.53(0.12)$ \\
\hline \multicolumn{5}{|l|}{ Ectopic pregnancy } \\
\hline Before surgery & $0.06(0.80)$ & $-0.25(0.29)$ & $0.46(0.04)$ & $-0.06(0.85)$ \\
\hline After surgery & $-\mathbf{0 . 4 3}(0.05)$ & $-0.29(0.20)$ & $-0.34(0.13)$ & $0.36(0.13)$ \\
\hline
\end{tabular}

The results are shown as the $r$-value of the Spearman correlation at $p<0.01$ andthe $95 \%$ confidence interval. The significance ( $P$ value) of the correlation is in parentheses and boldface values are statistically significant.

n.d., not determined. 
Table 4 Correlation between PIGF level and hormone concentrations

\begin{tabular}{lcccc}
\hline & E2 & P4 & T & \\
\hline Endometrial cycle phase & & & & \\
$\quad$ Mid secretive & $-0.17(0.48)$ & $0.10(0.69)$ & $0.04(0.87)$ & \\
$\begin{array}{l}\text { Intrauterine pregnancy } \\
\text { Early }\end{array}$ & $-0.01(0.99)$ & $0.48(0.10)$ & $-0.29(0.34)$ & n.d. \\
Post-term delivery & $0.25(0.52)$ & $0.13(0.73)$ & $-0.25(0.52)$ & $-0.06(0.85)$ \\
Ectopic pregnancy & & & $-0.23(0.52)$ \\
Before surgery & $\mathbf{1 . 0 0 ( < 0 . 0 0 1 )}$ & $-0.13(0.57)$ & $-0.30(0.19)$ & $-0.04(0.87)$ \\
After surgery & $-\mathbf{0 . 4 8 ( 0 . 0 3 )}$ & $-0.11(0.65)$ & $-\mathbf{0 . 4 4}(0.05)$ & $0.09(0.71)$ \\
\hline
\end{tabular}

The results are shown as the $r$-valueof the Spearman correlation at $p<0.01$ and a $95 \%$ confidence interval. The significance ( $P$ value) of the correlation is in parentheses and boldface values are statistically significant.

n.d., not determined.

IUP (Figure 1B). However, further analysis with a serum $\beta$-hCG cut-off level $(<1000 \mathrm{mIU} / \mathrm{mL})$ showed a significant difference in $\mathrm{P} 4$ levels between women with tubal EP with less than $1000 \mathrm{mIU} / \mathrm{mL} \beta$-hCG and women in the early stage of IUP $(3.65 \pm 0.77$ vs. $13.00 \pm 1.65$ $\mathrm{mIU} / \mathrm{mL}, \mathrm{P}<0.001)$. The levels of serum $\beta$-hCG were significantly lower in women with tubal EP than in women in the early stage of IUP (Table 1). Women with EP both before and after tubal surgeries had higher levels of VEGF-A than in the gestational agematched women with IUP (Figure 1D). The mean difference in VEGF-A levels between tubal EP prior to surgery and the early stage of IUP was $684.38 \mathrm{pg} / \mathrm{mL}(95 \% \mathrm{CI}$ : 420.54-948.22, $\mathrm{P}<0.001)$. However, no significant differences in T, PIGF, or ADAM12 levels alone were observed between women with tubal EP and gestational age-matched women with IUP (Figures 1C, E and F).

The diagnostic accuracy of the various parameters (E2, P4, T, VEGF-A, PIGF, and ADAM12 levels and the E2: P4 ratio) in the tubal EP and early IUP groups was evaluated by ROC analysis (Figures $2 \mathrm{~A}$ and $\mathrm{B}$ ). The area under the ROC curve represents the probability of correctly distinguishing between gestational age-matched women with tubal EP or IUP. The areas under the curves for serum E2, P4, and VEGF-A levels for the diagnosis of tubal EP were 0.99 (95\% CI: 0.98-1.00, P < 0.0001 ), 0.86 (95\% CI: $0.75-0.98, \mathrm{P}<0.0001$ ), and 0.94 (95\% CI: $0.86-1.00, \mathrm{P}<0.0001$ ), respectively. However, the areas under the curves for serum T, PIGF, and ADAM12 levels for the diagnosis of tubal EP were 0.61 (95\% CI: 0.42-0.80, P > 0.05), 0.47 (95\% CI: 0.26-0.68, $\mathrm{P}>0.05$ ), and 0.48 (95\% CI: $0.25-0.69$, P > 0.05), respectively. These ROC curve analyses showed that the identification of women with tubal EP could not rely on measurements of serum levels of T, PIGF, or ADAM12 alone. In addition, the areas under the curves for the E2: VEGF-A and E2: PIGF ratios for the diagnosis of tubal EP were 0.99 (95\% CI: $0.97-$ $1.00, \mathrm{P}<0.001)$ and 1.00 (95\% CI: $1.00-1.00, \mathrm{P}<0.001$ ), respectively (Figure $2 \mathrm{C}$ ).

\section{Discussion}

There is a need for a sensitive and specific diagnostic biomarker that can facilitate early diagnosis and permit timely treatment of tubal EP $[14,15]$. Currently, the limited specificity and sensitivity of circulating biomarkers for the early diagnosis of tubal EP has greatly restricted their reliability.

Table 5 Correlation between ADAM12 level and hormone concentrations

\begin{tabular}{|c|c|c|c|c|}
\hline & E2 & P4 & $\mathbf{T}$ & $\beta$-hCG \\
\hline \multicolumn{5}{|c|}{ Endometrial cycle phase } \\
\hline Mid secretive & $-0.33(0.15)$ & $-0.23(0.33)$ & $0.11(0.63)$ & n.d. \\
\hline \multicolumn{5}{|c|}{ Intrauterine pregnancy } \\
\hline Early & $0.36(0.22)$ & $-0.34(0.26)$ & $0.53(0.06)$ & $0.07(0.82)$ \\
\hline Post-term delivery & $0.12(0.77)$ & $-0.43(0.24)$ & $0.38(0.31)$ & $0.18(0.63)$ \\
\hline \multicolumn{5}{|l|}{ Ectopic pregnancy } \\
\hline Before surgery & $-0.13(0.57)$ & $1.00(<0.001)$ & $0.15(0.54)$ & $-0.31(0.18)$ \\
\hline After surgery & $-0.45(0.04)$ & $-0.20(0.40)$ & $-0.36(0.11)$ & $0.19(0.43)$ \\
\hline
\end{tabular}

The results are shown as the r-value of the Spearman correlation at $p<0.01$ anda $95 \%$ confidence interval. The significance ( $P$ value) of the correlation is in parentheses and boldface values are statistically significant.

n.d., not determined. 

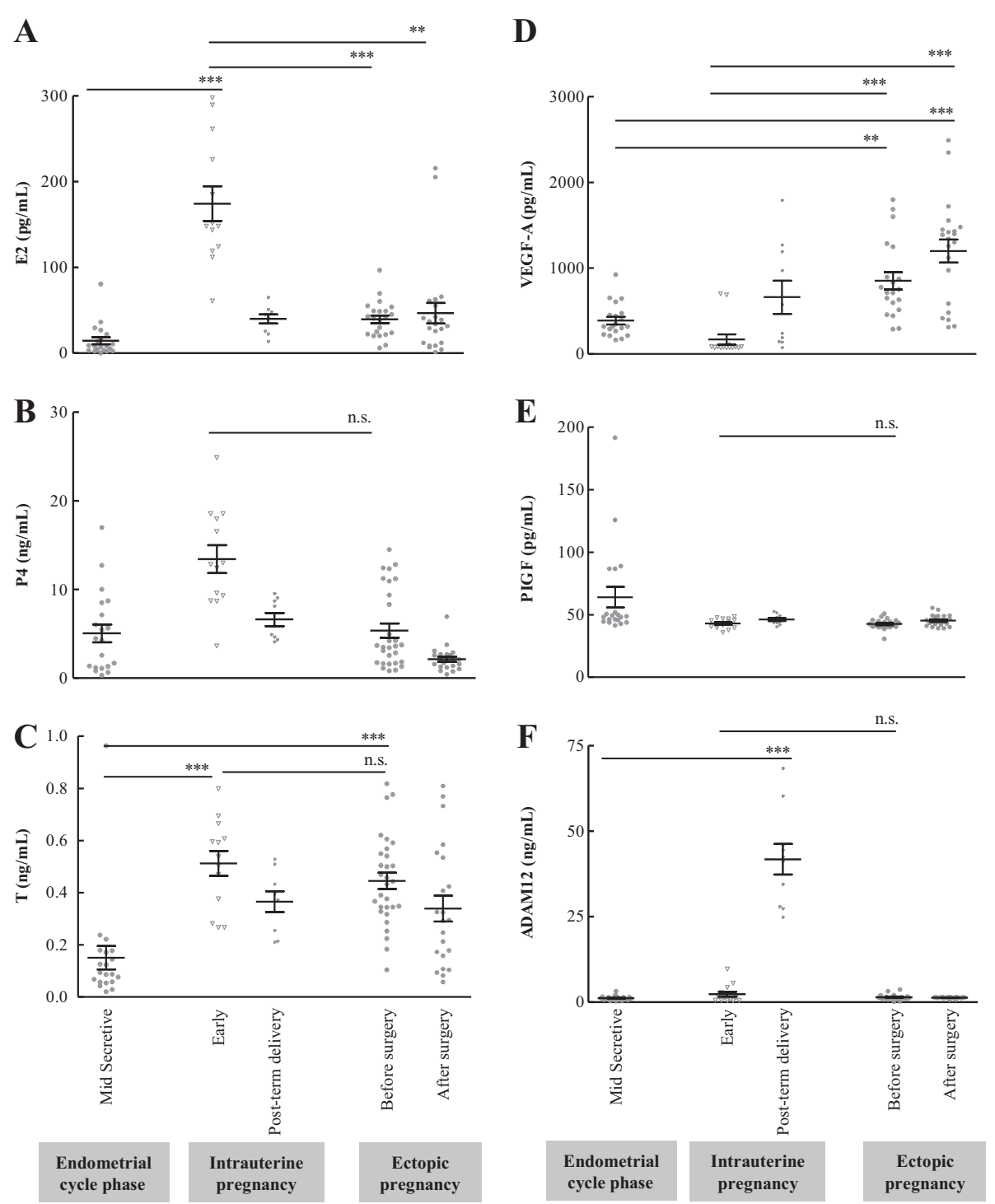

Figure 1 Serum levels of E2, P4, T, VEGF, PIGF, and ADAM12 in women with IUP divided into early IUP and post-term delivery subgroups, and in women with EP before and after tubal surgeries compared with women in the mid-secretive phase of the endometrial cycle. All data are expressed as the mean \pm SEM. A nonparametric, unpaired test (Kruskal-Wallis test) followed by Dunnett's posthoc test was used for multiple comparisons of continuous variables. ${ }^{*} P<0.01$, and ${ }^{* * *} P<0.001$. n.s., not significant.

The present study has significant strengths. First, this study shows in an independent and well-defined sample set that individual measurements of serum P4 levels were lower in women with tubal EP than gestational age-matched women with IUP, but this difference was not statistically significant. Sub-group analysis, however, provided a much more striking result. When samples were compared at a serum $\beta$-hCG level of less than 1000 $\mathrm{mIU} / \mathrm{mL}$, serum P4 levels differed significantly between the tubal EP and gestational age-matched IUP groups. These results suggest that using a combination of serum P4 and $\beta$-hCG levels can possibly differentiate a certain group of women with tubal EP from those with normal IUP. More importantly, we show that individual measurements of serum E2 or VEGF-A levels have significant advantages over serum $\mathrm{P} 4$ levels for distinguishing tubal EP from gestational age-matched IUP. Our data, together with that provided by others $[15,33]$, show that circulating E2 levels are higher in women with tubal EP than non-pregnant women in the mid-secretive phase of the menstrual cycle, but are lower than in gestational age-matched women with IUP. These findings indicate that abnormal E2 levels may interrupt the tubal microenvironment and ultimately lead to improper embryo implantation in the Fallopian tube. In line with previous studies [12,18-23] 
A

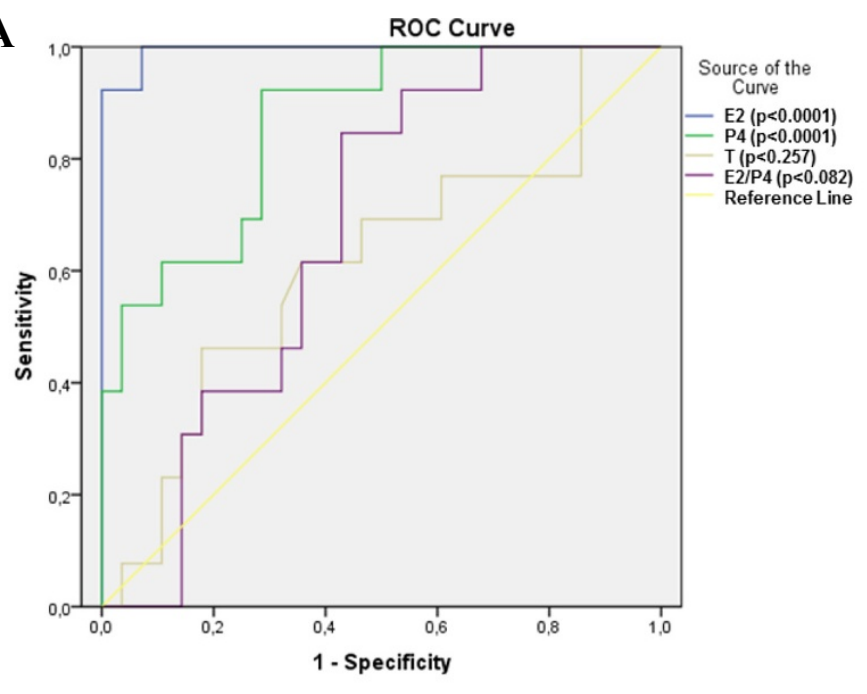

B

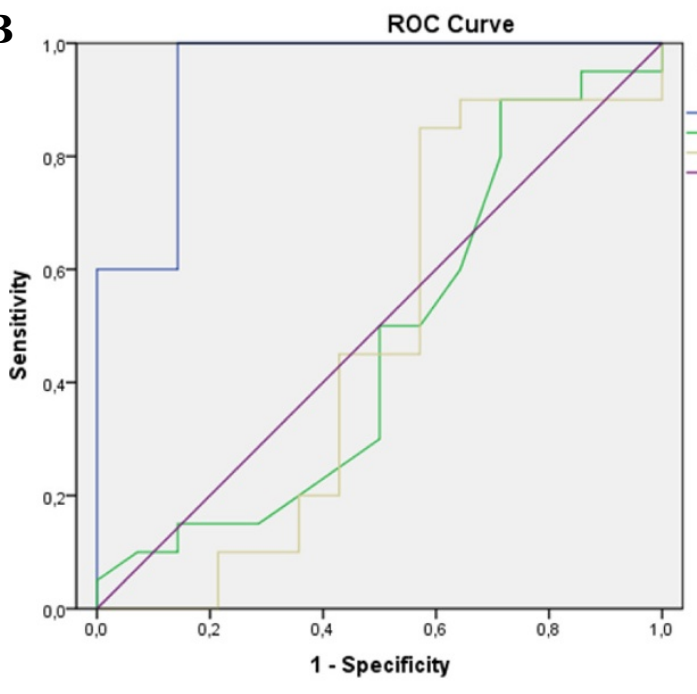

C

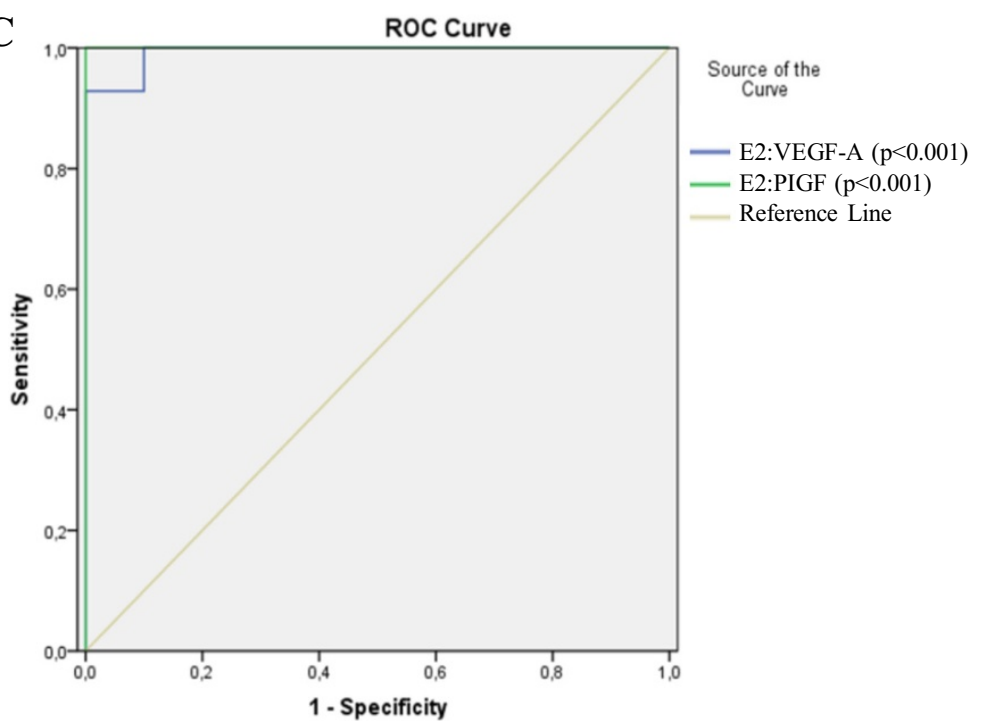

Figure 2 (See legend on next page.) 
(See figure on previous page.)

Figure 2 (A) E2, P4, T levels and the E2:P4 ratio as diagnostic tests for women with tubal EP were assessed by the receiver operating curve (ROC) test. ROC analysis was performed with SPSS version 16.0 for Windows, and statistical significance ( $P$ value) is indicated. The area under the curve was 0.99 (95\% Cl: 0.98-1.00) for E2, 0.86 (95\% Cl: 0.75-0.98) for P4, 0.61 (95\% Cl: 0.42-0.80) for T, and 0.67 (95\% Cl: 0.51-0.83) for the E2:P4 ratio. (B) VEGF, PIGF, and ADAM12 as diagnostic tests for women with tubal EP were assessed by the ROC test. The area under the curve was 0.94 (95\% Cl: 0.86-1.00) for VEGF, 0.47 (95\% Cl: 0.26-0.68) for PIGF, and 0.48 (95\% Cl: 0.25-0.69) for ADAM12. (C) The E2: VEGF-A and E2: PIGF ratio as diagnostic tests for women with tubal EP were assessed by the ROC test. The area under the curve was 0.99 (95\% Cl: 0.97-1.00) for the E2: VEGF-A ratio, and 1.00 (95\% Cl: 1.00-1.00) for the E2: PIGF ratio.

despite differences in the study populations, we have found a significant induction in VEGF-A levels in women with EP relative to gestational age-matched women with IUP. Using an increased cut-off of $200 \mathrm{pg} / \mathrm{mL}$, we have shown that all women with tubal EP ( $\mathrm{n}=33)$ had a serum VEGF-A level more than $200 \mathrm{pg} / \mathrm{mL}$, which is consistent with previous studies $[18,21]$. The data indicate that a serum VEGF-A level of greater than $200 \mathrm{pg} / \mathrm{mL}$ can be used to discriminate a tubal EP from a normal IUP in women. Additionally, we found that serum E2 and VEGF-A concentration measurements generated superior diagnostic accuracy. Taken together, these data suggest that E2 and VEGFA can be useful biomarkers for the early diagnosis of tubal EP.

The second important finding of the present study is that there are different correlations between the levels of steroid hormones and VEGF-A, PIGF, and ADAM12 in both the early stage of IUP and in tubal EP. This suggests that their in vivo biological functions should not be considered independently of each other. We show that, in contrast to the early stage of IUP, serum E2 levels do not correlate with serum VEGF-A levels but do correlate with serum PIGF levels in tubal EP. We also show that serum $\mathrm{T}$ levels correlate with serum VEGF-A levels and that serum P4 levels correlate with serum ADAM12 levels in tubal EP. Although highly suggestive, these significantly correlated data cannot prove that steroid hormones are responsible for the changes in the levels of VEGF-A, PIGF, and ADAM12 in the Fallopian tube. Embryonic implantation in the uterus is a complex developmental process that is likely mediated by a variety of molecules such as steroid hormones, growth factors, and cytokines [34]. However, little is known about the interactions of these molecules, especially in terms of tubal implantation [5,9]. Previous studies have demonstrated the use of combinations of circulating proteins for the diagnosis of $\mathrm{EP}$ $[12,22]$, and we show here that the E2: VEGF-A and E2: PIGF ratios can aid in distinguishing tubal EP from normal IUP. It will be of interest in future studies to validate the results from our study with additional cohorts and to determine whether alternative combinations of these markers may demonstrate improved performance.

\section{Possible mechanisms responsible for the regulation of VEGF/PIGF expression, secretion, and signaling pathways during the development of tubal EP}

To grow to the point of causing harm, a tubal EP requires the development of a local blood supply and angiogenesis at the tubal implantation site. It is thus reasonable to expand upon clinical research on circulating VEGF isoforms to understand the mechanisms by which their synthesis is regulated and to understand their biological functions during Fallopian tubal implantation. Such research would allow for a better understanding of the actual diagnostic values of VEGF-A and PIGF. In the human Fallopian tube, VEGF is localized in the epithelial cells, smooth muscle cells, and blood vessel cells in a region-specific manner [35,36], and significantly higher levels of tubal VEGF and VEGF receptor mRNAs are detected in women with a hydrosalpinx [37], which is defined as tubal dilation and abnormal fluid accumulation [6]. Moreover, in vitro studies have shown an increase in VEGF and soluble VEGF receptor secretion in human tubal epithelial cells and stromal fibroblasts in response to hypoxic stimulation [38]. It has been shown that VEGF-A and VEGF receptor mRNAs are significantly increased in the implantation site compared to non-implantation sites of human Fallopian tubes [39], and these are associated with trophoblastic invasion into the tubal wall in vivo [40] suggesting that the development of tubal EP could contribute to the elevation of circulating VEGF-A levels. Moreover, ligation of the Fallopian tube, which mimics the tubal occlusion that likely induces an EP in women, increases VEGF protein expression in rat Fallopian tubes [41].

Our results, together with those from other laboratories, provide a basis for proposing a working model for regulation and activation of VEGF isoforms and their receptor signaling pathways during tubal implantation. Disruption of the local environment such as a low oxygen level, possibly due to embryo implantation in the Fallopian tube, induces elevated levels of hypoxiainducible factors (HIFs) [42]. This leads to tubal VEGFA synthesis and secretion resulting in the abnormal levels of circulating VEGF-A seen in women with EP. HIF, a critical hypoxia sensor, is a heterodimeric complex composed of three alpha subunits (HIF-1 $\alpha$, HIF- $2 \alpha$, 
and HIF3 $\alpha$ ) and a stable beta subunit (HIF-1 $\beta$, also known as aryl hydrocarbon receptor nuclear translocator (ARNT)) [42]. Hypoxic HIF activity is controlled primarily through post-translational modification and stabilization of the HIF- $1 \alpha$ and HIF- $2 \alpha$ subunits, and HIF- $1 \beta$ expression levels constitute important determinants of hypoxia responsiveness [42]. It is well known that heterodimeric complexes of HIF- $1 \alpha / \beta$ translocate to the nucleus and activate several hypoxia-associated genes, including VEGF [16]. VEGF-A can form homodimers with itself and/or heterodimers with PIGF, and acts by binding to its two cell surface tyrosine kinase receptors, FLT-1 (VEGFR1) and KDR/FLK-1 (VEGFR2). PIGF binds only to FLT-1 (VEGFR1) [16]. Thus, implantation in the Fallopian tube leads to the coordinated activation of a transcriptional cascade in response to the presence of excessive hypoxia. As a result, tubal VEGF-A levels are increased and this activates the VEGF signaling cascades in an autocrine manner. On the other hand, increased levels of tubal VEGF causes them to be released into the circulation, and this leads to activation of the VEGF signaling cascades in a paracrine manner. Both autocrine and paracrine regulation may result in tubal fluid secretion, vascular defects, angiogenic dysfunction, and tubal wall damage. During normal pregnancy, VEGF isoforms are involved in building the placenta [16]. VEGFA is expressed in the human placenta throughout gestation [43], and placenta-specific PIGF has a similar role as VEGF during normal IUP [16]. We show that serum PIGF levels are significantly increased in the middle and late stages of IUP compared to the early stage of IUP. In contrast to VEGF-A, however, we were unable to find a significant difference in serum PIGF levels between women with tubal EP and gestational age-matched women with IUP. Some previous studies have indicated that serum PIFG levels are elevated in tubal EP compared to IUP [23,24]. This discrepancy may be due to the different ethnic backgrounds of the patients analyzed, the pooling of blood samples from different gestational-aged women with acute and chronic clinical presentation of EP, and the use of a non-gestational agematched IUP as a comparison control.

E2 has traditionally been considered the major hormonal regulator of the Fallopian tube [34]. E2 exerts its biological effects by binding to the estrogen receptor (ER), which exists as two different subtypes, ER $\alpha$ and ER $\beta$. Both ER subtypes are expressed in normal human Fallopian tubes [5,44-46]. Moreover, ER $\alpha$ is frequently lost in the implantation and non-implantation site (our unpublished data) of the Fallopian tube in women who have suffered from EP $[44,47]$. Although the VEGF gene promoter harbors the estrogen response element [47], whether E2 is able to directly regulate VEGF-A expression via the activation of ER signaling in human Fallopian tubes is not fully understood. On the other hand, animal studies suggest that E2 and hypoxia can cooperate to regulate the same target in the Fallopian tube. For example, the expression of erythropoietin, a potent antiinflammatory cytokine, is increased by both E2 and hypoxia in mouse Fallopian tubes both in vivo and in vitro [48]. Treatment with E2 followed by hypoxic stimulation significantly reduces VEGF-A protein synthesis and release in human endometrial tissues in vitro [49]. Because the $C$-terminal domain of HIF- $1 \beta$, a potent coactivator of ER-dependent transcription, is essential for the enhancement of ER transcription [50], E2-dependent regulation of VEGF expression and secretion may be indirect through HIF isoforms during the Fallopian tubal implantation. Furthermore, in vitro experiments have shown that insulinlike growth factor- 1 and interleukin- $1 \beta$ directly regulate VEGF and VEGFR expression in human tubal epithelial cells and stromal fibroblasts [51,52]. Collectively, these observations show that different molecules contribute to the regulation of VEGF synthesis and secretion, but their precise roles in tubal EP are not clearly understood. No existing mouse models can establish causative roles for factors implicated in the pathogenesis of EP [1,9], thus new animal models will need to be developed to specifically address these issues.

Although placenta-specific ADAM12 has been previously reported to distinguish EP from IUP $[12,26]$, our findings are in agreement with a recent finding by Horne et al. [27] that demonstrated the limited utility of single serum ADAM12 measurements as an early diagnostic biomarker for tubal EP.

\section{Limitations to the study}

A limitation of the study is the relatively small sizes of the patient groups, and these may not accurately represent the actual biomarker levels during the development and onset of tubal EP. Thus additional large-scale studies are needed to determine the changes in selected biomarker levels before onset of tubal EP to validate their utility in diagnosing tubal EP. Because it is ethically impossible to obtain tissues from early IUP and post-surgery EP patients, another limitation is that our study lacks data using Western blotting analysis and immunohistochemistry for determining VEGF-A, PIGF, and ADAM12 expression levels in these patients.

\section{Conclusions}

In summary, we have demonstrated that individual measurements of serum E2 or VEGF-A levels are strongly related to early pregnancy outcomes for women with IUP and EP, and pregnancy-associated E2 and VEGF-A levels may serve as biomarkers for the early diagnosis of tubal EP. Although our study also highlights the potential use of combined E2/VEGF-A or E2/PIGF measurements as promising diagnostic biomarkers for tubal EP, the limitations of our study warrant further investigation. Further studies 
using two relatively large prospective cohorts with welldefined and gestational age-matched tubal EP and IUP are warranted to confirm the clinical relevance of these correlations in women with tubal EP.

\section{Abbreviations}

EP: Ectopic pregnancy; IUP: Intrauterine pregnancy; E2: 17ß-estradiol; P4: Progesterone; T: Testosterone; $\beta$-hCG: Beta-human chorionic gonadotropin; VEGF-A: Vascular endothelial growth factor-A; PIGF: Placental growth factor; ADAM12: A distintegrin and metalloprotease protein 12.

\section{Competing interests}

The authors report no conflict of interest.

\section{Authors' contributions}

$S Z, X L, Y F, S S, J L$, and EE participated in the recruitment of patients, conducted the experiments, performed statistical analysis of the data, and made the tables and figures. HB provided clinical insights, interpreted the data, and edited the paper. RS designed, supervised and coordinated the study and drafted the manuscript. Each author has taken public responsibility for appropriate portions of the content and all authors have read and approved the final manuscript.

\section{Acknowledgments}

We thank Prof. Shaofen Zhang and Dr. Yu Ding (Department of Gynecology, Obstetrics and Gynecology Hospital of Fudan University, Shanghai, China) for their valuable comments on the manuscript and discussion during the current investigation.

\section{Funding}

This work was supported by the Swedish Medical Research Council (Grants 5859), the Sahlgrenska Academy Research Council, GöteborgsLäkaresällskap, the HjalmarSvensson Foundation, Fred G. and Emma E. Kanold's Foundation, Fredrik and Ingrid Thuring's Foundation, Anna Cederberg's Foundation, Tore Nilson's Foundation, ÅkeWiberg's Foundation, Wilhelm-Martina Lundgren's Foundation, the Wennergren Foundation, Jane and Dan Olsson's Foundation, and the Royal Society of Arts and Sciences in Gothenburg. The funding sources of this study were not involved in the study design, collection, analysis, or data interpretation, in the writing of the report, or in the decision to submit the paper for publication.

\section{Author details}

'Department of Gynecology, Obstetrics and Gynecology Hospital of Fudan University, Shanghai 200011, China. ${ }^{2}$ Department of Physiology/ Endocrinology, Institute of Neuroscience and Physiology, The Sahlgrenska Academy, University of Gothenburg, Gothenburg 40530, Sweden. ${ }^{3}$ Department of Integrative Medicine and Neurobiology, State Key Lab of Medical Neurobiology, Shanghai Medical College and Institute of Acupuncture Research (WHO Collaborating Center for Traditional Medicine), Institute of Brain Science, Fudan University, Shanghai 200032, China. ${ }^{4}$ Laboratory Center, Eye and Ear, Nose, Throat Hospital of Fudan University, Shanghai 200031, China. Institute of Bioscience, Fudan University, Shanghai 200032, China.

Received: 28 November 2012 Accepted: 7 February 2013 Published: 19 February 2013

\section{References}

1. Shaw JL, Dey SK, Critchley HO, Horne AW: Current knowledge of the aetiology of human tubal ectopic pregnancy. Hum Reprod Update 2010, 16:432-444

2. Barnhart KT: Clinical practice. Ectopic pregnancy. N Engl J Med 2009, 361:379-387.

3. Farquhar CM: Ectopic pregnancy. Lancet 2005, 366:583-591.

4. Jurkovic $D$, Wilkinson $\mathrm{H}$ : Diagnosis and management of ectopic pregnancy. BMJ 2011, 342:d3397.

5. Shao R, Feng Y, Zou S, Weijdegard B, Wu G, Brannstrom M, Billig H: The role of estrogen in the pathophysiology of tubal ectopic pregnancy. Am J Transl Res 2012, 4:269-278.
6. Shao R, Wang X, Wang W, Stener-Victorin E, Mallard C, Brannstrom M, Billig H: From mice to women and back again: Causalities and clues for Chlamydiainduced tubal ectopic pregnancy. Fertil Steril 2012, 98:1175-1185.

7. Shao R, Zhang SX, Weijdegard B, Zou S, Egecioglu E, Norstrom A, Brannstrom M, Billig H: Nitric oxide synthases and tubal ectopic pregnancies induced by Chlamydia infection: basic and clinical insights. Mol Hum Reprod 2010, 16:907-915.

8. Shao R, Zou S, Wang X, Feng Y, Brannstrom M, Stener-Victorin E, Billig H: Revealing the Hidden Mechanisms of Smoke-Induced Fallopian Tubal Implantation. Biol Reprod 2012, 86:131.

9. Shao R: Understanding the mechanisms of human tubal ectopic pregnancies: new evidence from knockout mouse models. Hum Reprod 2010, 25:584-587.

10. Cabar FR, Fettback PB, Pereira PP, Zugaib M: Serum markers in the diagnosis of tubal pregnancy. Clinics (Sao Paulo) 2008, 63:701-708.

11. Gerton GL, Fan XJ, Chittams J, Sammel M, Hummel A, Strauss JF, Barnhart K: A serum proteomics approach to the diagnosis of ectopic pregnancy. Ann N Y Acad Sci 2004, 1022:306-316.

12. Rausch ME, Sammel MD, Takacs P, Chung K, Shaunik A, Barnhart KT: Development of a multiple marker test for ectopic pregnancy. Obstet Gynecol 2011, 117:573-582

13. Segal $S$, Mercado R, Rivnay B: Ectopic pregnancy early diagnosis markers. Minerva Ginecol 2010, 62:49-62.

14. Barnhart K, Speicher DW: Molecular diagnosis of ectopic pregnancy. Expert Rev Mol Diagn 2011, 11:759-762.

15. Cartwright J, Duncan WC, Critchley HO, Horne AW: Serum biomarkers of tubal ectopic pregnancy: current candidates and future possibilities. Reproduction 2009, 138:9-22.

16. Andraweera PH, Dekker GA, Roberts $C T$ : The vascular endothelial growth factor family in adverse pregnancy outcomes. Hum Reprod Update 2012, 18:436-457.

17. Kveiborg M, Albrechtsen $R$, Couchman JR, Wewer UM: Cellular roles of ADAM12 in health and disease. Int J Biochem Cell Biol 2008, 40:1685-1702.

18. Daniel Y, Geva E, Lerner-Geva L, Eshed-Englender T, Gamzu R, Lessing JB, Bar-Am A, Amit A: Levels of vascular endothelial growth factor are elevated in patients with ectopic pregnancy: is this a novel marker? Fertil Steril 1999, 72:1013-1017.

19. Daponte A, Pournaras S, Zintzaras E, Kallitsaris A, Lialios G, Maniatis AN, Messinis IE: The value of a single combined measurement of VEGF, glycodelin, progesterone, PAPP-A, HPL and LIF for differentiating between ectopic and abnormal intrauterine pregnancy. Hum Reprod 2005, 20:3163-3166.

20. Fasouliotis SJ, Spandorfer SD, Witkin SS, Liu HC, Roberts JE, Rosenwaks Z: Maternal serum vascular endothelial growth factor levels in early ectopic and intrauterine pregnancies after in vitro fertilization treatment. Fertil Steril 2004, 82:309-313.

21. Felemban A, Sammour A, Tulandi T: Serum vascular endothelial growth factor as a possible marker for early ectopic pregnancy. Hum Reprod 2002, 17:490-492.

22. Mueller MD, Raio L, Spoerri S, Ghezzi F, Dreher E, Bersinger NA: Novel placental and nonplacental serum markers in ectopic versus normal intrauterine pregnancy. Fertil Steril 2004, 81:1106-1111.

23. Patrelli TS, Gizzo S, Plebani M, Basso D, Capobianco G, Bartolucci C, Modena $A B$, Rondinelli M, Nardelli GB: The trend of VEGF-A and PIGF in pregnant patients: a perspective case-control study on 214 women. Clin Exp Obstet Gynecol 2012, 39:57-64.

24. Daponte A, Pournaras S, Polyzos NP, Tsezou A, Skentou H, Anastasiadou F, Lialios G, Messinis IE: Soluble FMS-like tyrosine kinase-1 (sFlt-1) and serum placental growth factor (PIGF) as biomarkers for ectopic pregnancy and missed abortion. J Clin Endocrinol Metab 2011, 96:E1444-E1451.

25. Horne AW, Shaw JL, Murdoch A, McDonald SE, Williams AR, Jabbour HN, Duncan WC, Critchley HO: Placental growth factor: a promising diagnostic biomarker for tubal ectopic pregnancy. J Clin Endocrinol Metab 2011, 96:E104-E108

26. Beer LA, Tang HY, Sriswasdi S, Barnhart KT, Speicher DW: Systematic discovery of ectopic pregnancy serum biomarkers using 3-day protein profiling coupled with label-free quantitation. J Proteome Res 2011, 10:1126-1138.

27. Horne AW, Brown JK, Tong S, Kaitu'u-Lino T: Evaluation of ADAM-12 as a Diagnostic Biomarker of Ectopic Pregnancy in Women with a Pregnancy of Unknown Location. PLoS One 2012, 7:e41442. 
28. Rausch ME, Beer L, Sammel MD, Takacs P, Chung K, Shaunik A, Speicher D, Barnhart KT: A disintegrin and metalloprotease protein-12 as a novel marker for the diagnosis of ectopic pregnancy. Fertil Steril 2011, 95:1373-1378.

29. Kucera-Sliutz E, Schiebel I, Konig F, Leodolter S, Sliutz G, Koelbl H: Vascular endothelial growth factor (VEGF) and discrimination between abnormal intrauterine and ectopic pregnancy. Hum Reprod 2002, 17:3231-3234.

30. Noyes RW, Hertig AT, Rock J: Dating the endometrial biopsy. Am J Obstet Gynecol 1975, 122:262-263.

31. Zweig MH, Campbell G: Receiver-operating characteristic (ROC) plots: a fundamental evaluation tool in clinical medicine. Clin Chem 1993, 39:561-577.

32. DeLong ER, DeLong DM, Clarke-Pearson DL: Comparing the areas under two or more correlated receiver operating characteristic curves: a nonparametric approach. Biometrics 1988, 44:837-845.

33. Craig ZG, Ramey JM, Rochowiak MW, Brown LH, Teitelbaum H: Serum estradiol in the differential diagnosis of ectopic pregnancy. J Am Osteopath Assoc 1996, 96:461-464.

34. Wang H, Dey SK: Roadmap to embryo implantation: clues from mouse models. Nat Rev Genet 2006, 7:185-199.

35. Gordon JD, Mesiano S, Zaloudek CJ, Jaffe RB: Vascular endothelial growth factor localization in human ovary and fallopian tubes: possible role in reproductive function and ovarian cyst formation. J Clin Endocrinol Metab 1996, 81:353-359.

36. Lam PM, Briton-Jones C, Cheung CK, Lok IH, Yuen PM, Cheung LP, Haines C: Vascular endothelial growth factor in the human oviduct: localization and regulation of messenger RNA expression in vivo. Biol Reprod 2003, 68:1870-1876.

37. Lam PM, Briton-Jones C, Cheung CK, Po LS, Cheung LP, Haines C: Increased mRNA expression of vascular endothelial growth factor and its receptor (flt-1) in the hydrosalpinx. Hum Reprod 2003, 18:2264-2269.

38. Itoh H, Nasu K, Matsumoto H, Kawano Y, Yoshimatsu J, Narahara H: Hypoxia regulates vascular endothelial growth factor and soluble fms-like tyrosine kinase- 1 secretion by human oviductal epithelial cells and stromal fibroblasts. Fertil Steril 2006, 85(Suppl 1):1097-1102.

39. Lam PM, Briton-Jones C, Cheung CK, Leung SW, Cheung LP, Haines C: Increased messenger RNA expression of vascular endothelial growth factor and its receptors in the implantation site of the human oviduct with ectopic gestation. Fertil Steril 2004, 82:686-690.

40. Cabar FR, Pereira PP, Schultz R, Francisco RP, Zugaib M: Vascular endothelial growth factor and beta-human chorionic gonadotropin are associated with trophoblastic invasion into the tubal wall in ectopic pregnancy. Fertil Steril 2010, 94:1595-1600.

41. Kilic S, Tasdemir N, Lortlar N, Yuksel B, Budak G, Batioglu S: Vascular endothelial growth factor (VEGF) and inducible nitric oxide synthase (iNOS) immunoreactivities in rat ovaries and uterine tubes after tubal ligation: a controlled immunohistochemical study. Eur J Contracept Reprod Health Care 2008, 13:431-437

42. Ke Q, Costa M: Hypoxia-inducible factor-1 (HIF-1). Mol Pharmacol 2006, 70:1469-1480

43. Clark DE, Smith SK, Licence D, Evans AL, Charnock-Jones DS: Comparison of expression patterns for placenta growth factor, vascular endothelial growth factor (VEGF), VEGF-B and VEGF-C in the human placenta throughout gestation. J Endocrinol 1998, 159:459-467.

44. Horne AW, King AE, Shaw E, McDonald SE, Williams AR, Saunders PT, Critchley HO: Attenuated sex steroid receptor expression in fallopian tube of women with ectopic pregnancy. J Clin Endocrinol Metab 2009, 94:5146-5154

45. Shao R, Norstrom A, Weijdegard B, Egecioglu E, Fernandez-Rodriguez J, Feng Y, Stener-Victorin E, Brannstrom M, Billig H: Distinct Expression Pattern of Dicer 1 Correlates with Ovarian-Derived Steroid Hormone Receptor Expression in Human Fallopian Tubes during Ovulation and the Midsecretory Phase. J Clin Endocrinol Metab 2011, 96:E869-E877.

46. Shao R, Wang $X$, Weijdegard B, Norstrom A, Fernandez-Rodriguez J, Brannstrom $M$, Billig $H$ : Coordinate regulation of heterogeneous nuclear ribonucleoprotein dynamics by steroid hormones in the human Fallopian tube and endometrium in vivo and in vitro. Am J Physiol Endocrinol Metab 2012, 302:E1269-E1282.

47. Ulziibat S, Ejima K, Shibata Y, Hishikawa Y, Kitajima M, Fujishita A, Ishimaru T, Koji T: Identification of estrogen receptor beta-positive intraepithelial lymphocytes and their possible roles in normal and tubal pregnancy oviducts. Hum Reprod 2006, 21:2281-2289.
48. Masuda S, Kobayashi T, Chikuma M, Nagao M, Sasaki R: The oviduct produces erythropoietin in an estrogen- and oxygen-dependent manner. Am J Physiol Endocrinol Metab 2000, 278:E1038-E1044.

49. Punyadeera C, Thijssen VL, Tchaikovski S, Kamps R, Delvoux B, Dunselman GA, de Goeij AF, Griffioen AW, Groothuis PG: Expression and regulation of vascular endothelial growth factor ligands and receptors during menstruation and post-menstrual repair of human endometrium. $\mathrm{Mol}$ Hum Reprod 2006, 12:367-375.

50. Brunnberg S, Pettersson K, Rydin E, Matthews J, Hanberg A, Pongratz I: The basic helix-loop-helix-PAS protein ARNT functions as a potent coactivator of estrogen receptor-dependent transcription. Proc Natl Acad Sci U S A 2003, 100:6517-6522.

51. Nasu K, Itoh H, Yuge A, Kawano Y, Narahara H: Insulin-like growth factor-I regulates vascular endothelial growth factor secretion by human oviductal epithelial cells and stromal fibroblasts. J Soc Gynecol Investig 2006, 13:368-371.

52. Nasu K, Itoh H, Yuge A, Kawano Y, Yoshimatsu J, Narahara H: Interleukin1 beta regulates vascular endothelial growth factor and soluble fms-like tyrosine kinase- 1 secretion by human oviductal epithelial cells and stromal fibroblasts. Gynecol Endocrinol 2006, 22:495-500.

\section{doi:10.1186/1479-5876-11-44}

Cite this article as: Zou et al:: Comparison of the diagnostic values of circulating steroid hormones, VEGF-A, PIGF, and ADAM12 in women with ectopic pregnancy. Journal of Translational Medicine 2013 11:44.

\section{Submit your next manuscript to BioMed Central and take full advantage of:}

- Convenient online submission

- Thorough peer review

- No space constraints or color figure charges

- Immediate publication on acceptance

- Inclusion in PubMed, CAS, Scopus and Google Scholar

- Research which is freely available for redistribution 